\title{
O uso de lentes intra-oculares em pacientes portadores de fianseníase
}

TOL usage in leprosy patients

$\begin{array}{lrll}\text { Edmundo } & \text { Frota } & \text { de } & \text { Almeida } \\ \text { Luciana } & \text { Negrão } & \text { Frota } & \text { de }\end{array}$

${ }^{1}$ Doutor em Oftalmologia pela Universidade Federal de Minas Gerais (UFMG), médico oftalmologista do Hospital Marcelo Cândia, Belém, PA.

2 Estudante do $4^{\circ}$ ano de Medicina da Universidade Estadual do Pará (UEPA).

Endereço para correspondência: Av. Conselheiro Furtado, 2818/14000 - Belém (PA) CEP 66063-060. E-mail: ealmeida@nautilus.com.br

INTRODUÇÃO

As lentes intra-oculares (LIO) foram pela primeira vez implantadas em 1949. Embora existam várias publicações a respeito das técnicas cirúrgicas, tipos de LIO utilizadas, aparelhos etc, raras são encontradas a respeito do seu uso em pacientes portadores do Mal de Hansen (MH); com exceção de uma publicação em 1989, em que um dos autores apresentou 35 casos de implantes de LIO em pacientes portadores desta doença. Nessa publicação, o autor observou que as complicações decorrentes desse procedimento são idênticas àquelas dos pacientes não portadores de Hanseníase ${ }^{(1)}$.

O receio de utilização da LIO nessa patologia repousa no fato de haver grande incidência de iridociclite hansênica nesses pacientes. Em verdade, o encontro dessa alteração não é uma condição freqüente ${ }^{(2-3)}$. O que se observa são alterações degenerativas que podem ser confundidas com uveíte $^{(4-5)}$. Mesmo no caso de comprovação da uveíte, a LIO é bem tolerada, desde que se opere fora do estado agudo e se utilize corticóide local instilado mais freqüentemente ${ }^{(1)}$.

A indicação da LIO nesses pacientes justifica-se pelas graves seqüelas incapacitantes por eles apresentadas, tais como: ausência das mãos, antebraços, braços e destruição da base do nariz, que acaba por dificultar o uso de óculos para a correção da afacia. Operá-los sem o uso da LIO seria condená-los à dependência de alguém para retirar-lhes e colocar-lhes os óculos ao dormir e ao tomar banho, por exemplo. Deve-se também considerar a qualidade de visão que a LIO propicia, além de permitir que o próprio paciente examine suas úlceras plantares já que, mesmo naqueles em que os 
membros superiores são perfeitos, pode haver perda da sensibilidade tátil, restando a visão como único recurso ${ }^{(1)}$.

\section{MÉTODOS}

Examinaram-se 122 olhos de 80 pacientes portadores de $\mathrm{MH}$, que foram submetidos à facectomia extracapsular (FEC) com implante LIO de câmara posterior de $7 \mathrm{~mm}(73 \%)$ ou à facoemulsificação (FACO), com o implante de LIO de $5,25 \mathrm{~mm}$ (27\%), que foram agrupados no grupo $\mathrm{MH}$.

Esses pacientes foram selecionados pelos autores no Centro de Referência Dermatológica Dr. Marcelo Cândia, Belém, PA, no período de novembro de 1997 a junho de 1998, estando em sua grande maioria de alta medicamentosa e apresentando apenas seqüelas da doença.

Os pacientes foram operados por único cirurgião (E.F.A.S.), utilizando as técnicas de FACO e FEC com pequenas variações. No pós-operatório, foram utilizadas corticoterapia e antibioticoterapia sob a forma de colírios, examinando-os inicialmente no $1^{\circ} \mathrm{e} 5^{\circ}$ dia do pós-operatório, semanalmente por um mês e a seguir uma vez por mês, por um período de 6 meses. Os dados coletados para o trabalho foram obtidos no $6^{\circ}$ mês de exame.

No grupo controle (GC), foram selecionados aleatoriamente 71 pacientes submetidos a FACO e FEC, operados pelo mesmo cirurgião, com o mesmo tempo de seguimento. Esses pacientes não eram portadores de doença sistêmica ou ocular, apresentando como única alteração pré-operatória a presença de catarata senil.

Como método estatístico, foi utilizado o qui-quadrado, corrigido pelo teste de Yates, considerando o valor do $\mathrm{p}=0,05$.

\section{RESULTADOS}

Dos 80 pacientes do grupo $\mathrm{MH}, 52(65 \%)$ eram do sexo masculino e 28 (35\%) do sexo feminino, com idade variando entre 37 a 98 , média de 68 anos.

Quanto à forma clínica da doença, $60(75 \%)$ dos pacientes pertenceram à forma Virchowiana (MHV); $8(10 \%)$, à forma Tuberculóide (MHT); 9 (11,25\%), ao grupo Dimorfo (MHD) e 3 $(3,75 \%)$, ao grupo Indeterminado (MHI).

Dos 122 olhos estudados, foram observadas algumas alterações oculares características da doença, mas que não têm relação com os procedimentos cirúrgicos utilizados, tais como: hiperemia conjuntival $(7,4 \%)$, ausência de sensibilidade corneana $(7,4 \%)$, sensibilidade diminuída $(25,4 \%)$, opacidade corneana $(20,49 \%)$, presença de úlcera $(1,7 \%)$ e vasos na córnea $(1,7 \%)$, atrofia iriana em 15 olhos, sendo $9(7,38 \%)$ do mesoderma, $1(0,82 \%)$ do epitélio pigmentar e $5(4,10 \%)$ de ambos.

Foram constatados, no entanto, achados que podem estar relacionados à cirurgia e/ou ao implante de LIO que estiveram ausentes no grupo controle, tais como: ausência de reflexos pupilares em 21 olhos $(17,2 \%)$, reflexos pupilares diminuídos em $13(10,7 \%)$, pupila ovalar em $17(13,9 \%)$, piriforme em 4 (3,3\%), e midríase em $18(14,8 \%)$ dos casos. Observou-se também a presença de sinéquias em 14 olhos $(11,48 \%)$, sendo $1(0,82 \%)$ sinéquia anterior e $13(10,66 \%)$ sinéquias posteriores (íris-LIO); e precipitados ceráticos tipo "Mutton fat" em 5 $(4,10 \%)$ dos casos (Figura 1$)$.

Com relação à LIO, observou-se posição descentrada em 8 $(6,6 \%)$ dos olhos estudados, precipitados inflamatórios tipo "Mutton fat" em 3 (2,5\%), pigmentos em sua superfície em 10 $(8,2 \%)$ e captura em $9(7,4 \%)$. Estas duas últimas alterações também estiveram presentes no grupo controle, porém com uma ocorrência inferior (Tabela 1). Os achados de células e "flare" na câmara anterior e no vítreo foram semelhantes em ambos os grupos, assim como a ocorrência de opacificação da cápsula posterior.

Dos 122 olhos operados, observou-se acuidade visual (AV) menor ou igual a $0,2 \mathrm{em} 18(17,3 \%)$; visão entre 0,3 e 0,5 em 42 (40,39\%); de 0,6 a 0,9 em 37 (35,58\%) e AV igual a 1,0 em $7(6,73 \%)$ (Figura 2).

\section{DISCUSSÃO}

As primeiras publicações acerca da utilização da LIO em pacientes portadores de $\mathrm{MH}$ mostraram não haver diferença entre os portadores desta doença e os pacientes normais ${ }^{(1,6)}$.

Neste trabalho, observou-se que houve maior número de complicações quando se comparou o grupo $\mathrm{MH}$ ao grupo

\begin{tabular}{|lcc|}
\hline \multicolumn{3}{|c|}{ Tabela 1. Achados relacionados à presença da LIO } \\
Achados & MH & GC \\
Descentrado x LIO & 8 & - \\
Pigmentos & 10 & 2 \\
Precipitados & 3 & - \\
Captura $\times$ Midríase & 9 & 1 \\
$\mathrm{p}=0,05 ; \mathrm{MH}=$ Mal de Hansen; GC = Grupo controle & \\
\hline
\end{tabular}

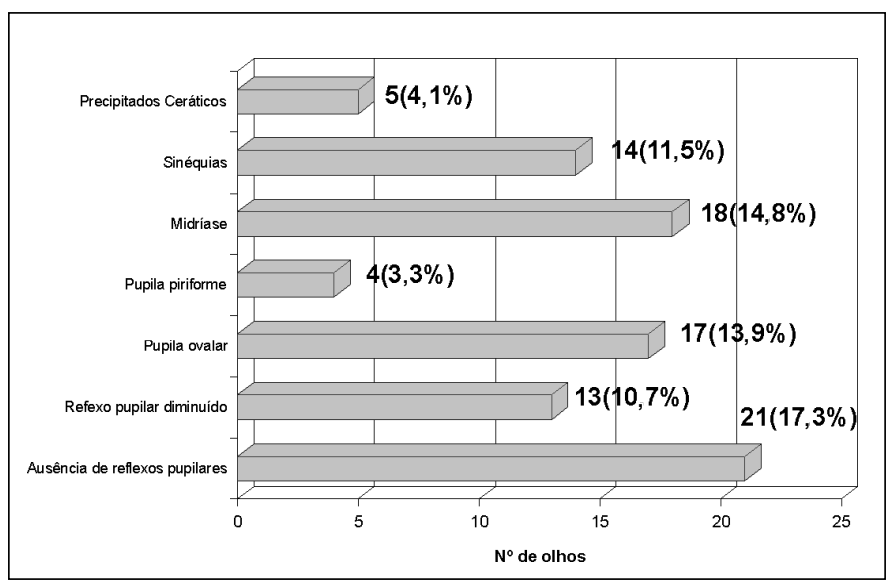

Figura 1 - Achados exclusivos do grupo MH 


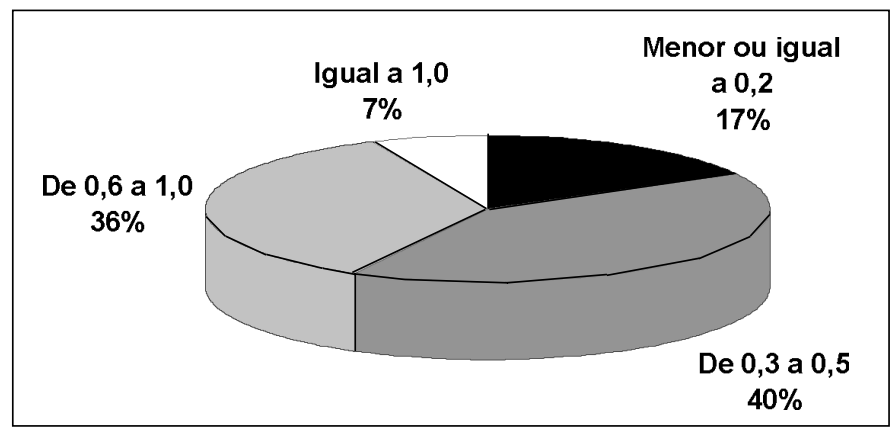

Figura 2 - Demonstrativo da acuidade visual do grupo MH

controle. Assim, verificaram-se alterações irianas significativas, como a midríase paralítica, com conseqüente ausência e/ ou diminuição de reflexos pupilares que são decorrentes das graves alterações atróficas do mesoderma e/ou do epitélio pigmentário da íris, existentes antes da cirurgia e comuns na hansenías ${ }^{(1,7)}$. O rompimento do músculo esfincteriano da pupila, causado pela extração do núcleo na técnica extracapsular, é o responsável pela midríase paralítica encontrada. Tais alterações são decorrentes de processo degenerativo iriano $^{(2-3)}$.

No que diz respeito à presença de alterações inflamatórias decorrentes da cirurgia e à presença da LIO, em comparação com o grupo controle, houve maior incidência de precipitados ceráticos; sinéquias anteriores e posteriores; precipitados inflamatórios sobre a LIO. Outras complicações encontradas, além das reações inflamatórias, foram: posição descentrada da LIO (mesmo nos casos em que foram utilizadas lentes intra-oculares de $7 \mathrm{~mm}$ ) e captura da LIO sem o acompanhamento de midríase, mostrando, assim, um comportamento diferente do GC.

É aconselhado, então, que se utilize corticóide sob a forma de colírio previamente à cirurgia ${ }^{(1)}$ e por um tempo mais prolongado após a mesma a fim de diminuir as reações inflamatórias.

Ao analisar-se a AV, verificou-se grande diferença entre os dois grupos, obtendo o grupo controle melhor acuidade visual. No entanto, há de se considerar outros achados que interferiram nessa avaliação, como a presença de lagoftalmo, opacidades corneanas, presença de vasos na córnea entre outras. Isto, porém, não invalida a indicação cirúrgica e uso da
LIO nesses pacientes, já que, com certeza, eles adquirem uma qualidade de visão muito melhor do que se não houvesse sido implantada a LIO, além das razões quanto ao grau de incapacidades já referidas.

Conclui-se, assim, que o uso de LIO em pacientes portadores de $\mathrm{MH}$ é um procedimento seguro, muito embora curse com processo inflamatório mais intenso no pós-operatório, quando comparado aos pacientes não portadores de Hanseníase. No entanto, em função do grande benefício que a LIO traz a esses pacientes e, em vista das seqüelas físicas próprias da doença, é inquestionável sua utilização.

A B S T RAC T

Purpose: To evaluate the ocular alterations due to cataract surgery with IOL implant in leprosy patients and compare them with patients without leprosy. Methods: In this study, 122 leprosy patient eyes and 71 eyes from patients without leprosy underwent extracapsular cataract surgery and/or phacoemulsification with IOL implant and were examined periodically after the operation. Results: Ocular alterations due to surgery and IOL presence were found more often in leprosy patients. Conclusions: IOL used in leprosy patient is an appropriate procedure when we face patients with the disease handicaps.

Keywords: Lenses, intraocular; Cataract extraction; Leprosy

\section{REFERENCIAS}

1. Almeida EF, Oréfice F. Lente intra-ocular em portadores de Hansen. Rev Bras Oftalmol 1989;48:205-7.

2. Oliveira Neto HL, Silva JLM, Manso PG, Botene IM, Sartori MBF. Envolvimento ocular na hanseníase: estudo em pacientes de ambulatório. Arq Bras Oftalmol 1996;59:162-6.

3. Oréfice F, Boratto LM. Estudo da clínica ocular de hansenianos em hospital de dermatologia sanitária. A prevenção em nossas mãos. Arq Bras Oftalmol 1990;53:13-7

4. Courtright P, Johnson G. Prevention of blindness in leprosy. London: International Center for Eyehealth; 1988.

5. Oréfice F, Campos WR. Hansen. In: Oréfice F, Belfort Jr R. Uveítes. São Paulo: Rocca; 1987. p. 265-72.

6. Alexander TK, Suriyawnsh I. Posterior chamber intraocular lenses in the rehabilitation of leprosy patients [abstract]. In: $13^{\text {th }}$ International Congress of Leprosy; 1988. Holanda: Christian Medical College; 1988. p.258.

7. Almeida EF. Mal de Hansen. Arq Bras Oftalmol 1992;55:209-10.

ABO ELETRÔNICO

Novo site

Acesso: $\quad$ fitt $p: / / w w w . a b o n e t . c o m .6 r$ 